\title{
AVALIAÇÃO DAS ESPÉCIES DE Plasmodium ENVOLVIDAS NOS CASOS CONFIRMADOS DE MALÁRIA NO ESTADO DE SÃO PAULO, 2012-2014
}

\author{
VALUATION OF Plasmodium SPECIES INVOLVED IN CONFIRMED MALARIA \\ CASES IN SÃO PAULO STATE, 2012-2014
}

\author{
R. G. S. OLIVEIRA ${ }^{1}$, E. M. N. DE PAULA², R. B. MEIRELLES-BARTOLI², A. A. B. CARVALHO ${ }^{1}$
}

\section{RESUMO}

A malária tem como agente etiológico um protozoário do gênero Plasmodium, cuja transmissão se dá por meio da picada do mosquito do gênero Anopheles que, por sua vez, já esteja infectado pelo protozoário. Os números de casos dessa doença no Estado de São Paulo (ESP), em geral, não são autóctones e apresentam queda desde o ano de 2012. O objetivo desse estudo foi determinar as espécies de Plasmodium relacionadas com os casos notificados de malária no ESP de 2012 a 2014. Trata-se de um estudo descritivo com base nos dados obtidos por meio de um levantamento realizado no sistema de informações DATASUS do Ministério da Saúde. Entre 2012 e 2014, foram notificados 2238 casos. Destas, foram 911 notificações confirmadas no ano de 2012, sendo 184 para $P$. falciparum, 476 de $P$. falciparum aliado ao gametócito de $P$. falciparum, 120 para $P$. vivax e 131 casos para $P$. falciparum aliado ao $P$. vivax. Já no ano de 2013, houve redução para 787 casos, sendo que dentre os casos, 172 foram causados por $P$. falciparum, 398 por $P$. falciparum com gametócito de $P$. falciparum, 113 por $P$. vivax e 104 por P. falciparum com P.vivax. Por fim, em 2014 foram 540 casos, sendo que 102 foram causados por $P$. falciparum, 281 por $P$. falciparum com gametócito de $P$. falciparum, 82 por $P$. vivax e 75 por $P$. falciparum com $P$. vivax. Conclui-se que o maior causador da malária no ESP foi o $P$. falciparum com gametócito de P. falciparum. A partir disso, é possível direcionar medidas de prevenção e realizar tratamentos específicos para cada espécie. A proteção individual é indispensável para a prevenção da malária.

PALAVRAS-CHAVE: VETOR. CASOS ALÓCTONES. VIGILÂNCIA EPIDEMIOLÓGICA. Plasmodium. PROTOZOÁRIO.

ÁREA TEMÁTICA: Zoonoses

\footnotetext{
1 Faculdade de Ciências Agrárias e Veterinárias da Universidade Estadual Paulista (UNESP) - Câmpus de Jaboticabal

2 Universidade Federal de Goiás (UFG), Regional Jataí, Unidade Jatobá, Laboratório de Sanidade Animal

*rachelgaleno@gmail.com
} 